University of Montana

ScholarWorks at University of Montana

$11-2009$

\title{
Wolverine Gene Flow Across a Narrow Climatic Niche
}

Michael K. Schwartz

University of Montana - Missoula, mkschwartz@fs.fed.us

Jeffrey P. Copeland

Neil J. Anderson

John R. Squires

Robert M. Inman

See next page for additional authors

Follow this and additional works at: https://scholarworks.umt.edu/wildbio_pubs

Part of the Life Sciences Commons

Let us know how access to this document benefits you.

\section{Recommended Citation}

Schwartz, Michael K.; Copeland, Jeffrey P.; Anderson, Neil J.; Squires, John R.; Inman, Robert M.;

McKelvey, Kevin Scot; Pilgrim, Kristine L.; Waits, Lisette P.; and Cushman, Samuel A., "Wolverine Gene Flow Across a Narrow Climatic Niche" (2009). Wildlife Biology Faculty Publications. 74.

https://scholarworks.umt.edu/wildbio_pubs/74

This Article is brought to you for free and open access by the Wildlife Biology at ScholarWorks at University of Montana. It has been accepted for inclusion in Wildlife Biology Faculty Publications by an authorized administrator of ScholarWorks at University of Montana. For more information, please contact scholarworks@mso.umt.edu. 
Authors

Michael K. Schwartz, Jeffrey P. Copeland, Neil J. Anderson, John R. Squires, Robert M. Inman, Kevin Scot McKelvey, Kristine L. Pilgrim, Lisette P. Waits, and Samuel A. Cushman 


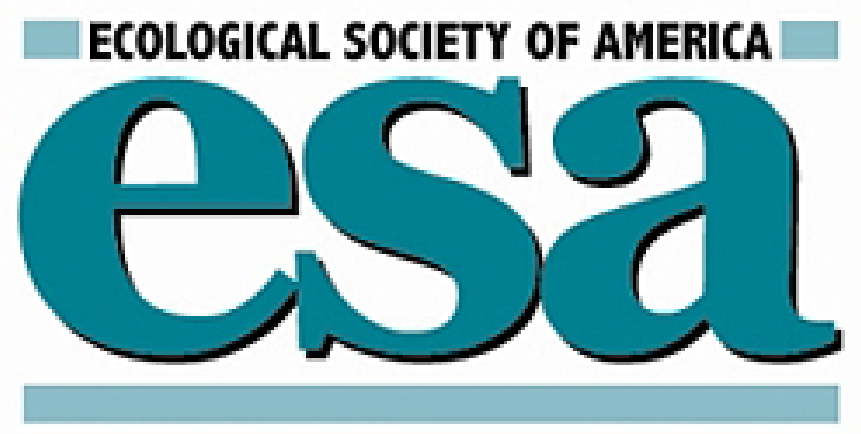

Wolverine Gene Flow across a Narrow Climatic Niche

Author(s): Michael K. Schwartz, Jeffrey P. Copeland, Neil J. Anderson, John R. Squires, Robert M. Inman, Kevin S. McKelvey, Kristy L. Pilgrim, Lisette P. Waits and Samuel A.

Cushman

Source: Ecology, Vol. 90, No. 11 (Nov., 2009), pp. 3222-3232

Published by: Ecological Society of America

Stable URL: http://www.jstor.org/stable/25592862

Accessed: 06/05/2014 15:54

Your use of the JSTOR archive indicates your acceptance of the Terms \& Conditions of Use, available at http://www.jstor.org/page/info/about/policies/terms.jsp

JSTOR is a not-for-profit service that helps scholars, researchers, and students discover, use, and build upon a wide range of content in a trusted digital archive. We use information technology and tools to increase productivity and facilitate new forms of scholarship. For more information about JSTOR, please contact support@ jstor.org. 


\title{
Wolverine gene flow across a narrow climatic niche
}

\author{
Michael K. Schwartz, ${ }^{1,5}$ Jeffrey P. Copeland, ${ }^{1}$ Neil J. Anderson, ${ }^{2}$ John R. Squires, ${ }^{1}$ Robert M. Inman, ${ }^{3}$ \\ Kevin S. McKelvey, ${ }^{1}$ Kristy L. Pilgrim, ${ }^{1}$ Lisette P. Waits, ${ }^{4}$ and Samuel A. Cushman ${ }^{1}$ \\ ${ }^{1}$ USDA Forest Service Rocky Mountain Research Station, 800 East Beckwith, Missoula, Montana 59801 USA \\ ${ }^{2}$ Montana Fish, Wildlife, and Parks, 1400 South 19th Avenue, Bozeman, Montana 59717 USA \\ ${ }^{3}$ Wildlife Conservation Society, 301 North Wilson Avenue, Bozeman, Montana 59715 USA \\ ${ }^{4}$ Department of Fish and Wildlife Resources, University of Idaho, Moscow, Idaho 83844-1136 USA
}

\begin{abstract}
Wolverines (Gulo gulo) are one of the rarest carnivores in the contiguous United States. Effective population sizes in Montana, Idaho, and Wyoming, where most of the wolverines in the contiguous United States exist, were calculated to be 35 (credible limits, 2852) suggesting low abundance. Landscape features that influence wolverine population substructure and gene flow are largely unknown. Recent work has identified strong associations between areas with persistent spring snow and wolverine presence and range. We tested whether a dispersal model in which wolverines prefer to disperse through areas characterized by persistent spring snow cover produced least-cost paths among all individuals that correlated with genetic distance among individuals. Models simulating large preferences for dispersing within areas characterized by persistent spring snow explained the data better than a model based on Euclidean distance. Partial Mantel tests separating Euclidean distance from spring snow-cover-based effects indicated that Euclidean distance was not significant in describing patterns of genetic distance. Because these models indicated that successful dispersal paths followed areas characterized by spring snow cover, we used these understandings to derive empirically based least-cost corridor maps in the U.S. Rocky Mountains. These corridor maps largely explain previously published population subdivision patterns based on mitochondrial DNA and indicate that natural colonization of the southern Rocky Mountains by wolverines will be difficult but not impossible.
\end{abstract}

Key words: corridors; effective population size; geographic information system; Gulo gulo; landscape resistance; least-cost paths; population genetics; wolverines.

\section{INTRODUCTION}

Habitat fragmentation has been shown to decrease dispersal, increase mortality (Fahrig et al. 1995), and reduce genetic diversity of wildlife populations (Saccheri et al. 2001, Goossens et al. 2006), thereby increasing extinction risks (Allendorf and Luikart 2006). Despite the clear importance of habitat connectivity for population persistence, specific factors mediating connectivity are largely unknown for most species (Bowne and Bowers 2004). Thus, managers and conservationists face a unique challenge in trying to enhance connectivity without species-specific information on movement, dispersal, and gene flow.

One such species where this challenge exists is the wolverine (Gulo gulo), a member of the mustelid family known for large home ranges (between $73 \mathrm{~km}^{2}$ and $\left.>950 \mathrm{~km}^{2}\right)$, exceedingly low densities $(0.3-6.2$ wolverine $/ 1000 \mathrm{~km}^{2}$ ) and long distance movements (Hornocker and Hash 1981, Lofroth and Krebs 2007). In fact, movements exceeding $150 \mathrm{~km}$ are not uncommon for

Manuscript received 7 July 2008; revised 4 February 2009; accepted 6 February 2009. Corresponding Editor: E. M. Schauber.

${ }^{5}$ E-mail: mkschwartz@fs.fed.us both sexes of wolverines (Copeland 1996, Inman et al. 2004) with reports of dispersal events as far as $378 \mathrm{~km}$ (Gardner et al. 1986, Moriarty et al. 2009). The wolverine is also a species of management interest and has recently been considered for listing under the U.S. Endangered Species Act (USFWS 2008).

Initial beliefs by researchers were that wolverines could persist in a broad array of habitat types (Pasitschniak-Arts and Lariviere 1995). More recently, this view has been challenged as fine-scale wolverine occurrence, documented via radiotelemetry, has been associated with high elevation alpine and avalanche environments (Copeland et al. 2007, Krebs et al. 2007, Lofroth and Krebs 2007). At a broader scale, the only habitat feature that has been correlated with the historical distribution of wolverines in North America is spring snow cover (Aubry et al. 2007; J. P. Copeland et al., unpublished manuscript). J. P. Copeland et al. (unpublished manuscript) suggest that wolverines are obligate habitat specialists that require spring snow cover. This is partially due to female wolverine's preference for denning in snow caves (Magoun and Copeland 1998). However, this ecological association with spring snow cover also extends to year-round locations throughout the species worldwide distribution (J. P. Copeland et al., unpublished manuscript). What 
remains unknown is the degree to which this ecological association affects dispersal, colonization, and gene flow.

One way to investigate the influence of landscape features on gene flow is to transform landscape features into putative costs to movement, derive matrices of leastcost paths among individuals across these hypothetical landscapes, and then correlate the least-cost paths with matrices of genetic relatedness among individuals (Manel et al. 2003, Coulon et al. 2006, Cushman et al. 2006, Cushman et al. 2009). For example, Cushman et al. (2006) used least-cost path modeling with black bears (Ursus americanus) to show that patterns of genetic structure were primarily related to landscape gradients of land cover and elevation. Using a similar approach, McRae and Beier (2007) modeled landscapes as electrical circuits with movement resistance modeled as resistors in an interconnected web. While McRae and Beier (2007) investigated wolverine population substructure in relation to the physical shape of the wolverine's distribution, with all nodes within the range having equal resistance, their method is compatible with Cushman et al.'s (2006) multiple-model approach.

When using genetic patterns to infer connectivity, it is often unclear if the genetic pattern has arisen recently or if there is a significant time lag associated with the pattern. The longer the time lag between changes in connectivity and resultant genetic structure, the less pertinent the results are for directing current management and the more difficult the interpretation becomes. The time lag between a change in connectivity and its genetic detectability is directly related to effective population size (Nei and Chakravarti 1977), with small effective population sizes being associated with rapid divergence. Historically, estimation of effective population size required two temporally separated samples (reviewed in Schwartz et al. 1998), precluding its calculation in many cases. Recently, estimates of effective population size based on single samples have been developed (Tallmon et al. 2008, Waples and Do 2008), allowing estimates to be based on the same samples used to determine spatial patterns.

The bioclimatic envelope hypothesis provided by $\mathbf{J}$. P. Copeland et al. (unpublished manuscript) defines wolverine distribution as a discrete space within which we can investigate questions of wolverine gene flow. Here, using wolverine samples from across its distribution in the U.S. Rocky Mountains, we ask the following questions: (1) Does the arrangement of areas of persistent spring snow cover explain the observed genetic distance among individuals after controlling for the effects of Euclidean distance and (2), if so, what major movement pathways (corridors) are suggested by our models that link areas of spring snow? We then evaluate effective population size, to provide inference for the time lag associated with these genetic patterns. Last, we use these findings to evaluate previously published subpopulation divisions and assess colonization potential between extant popu-

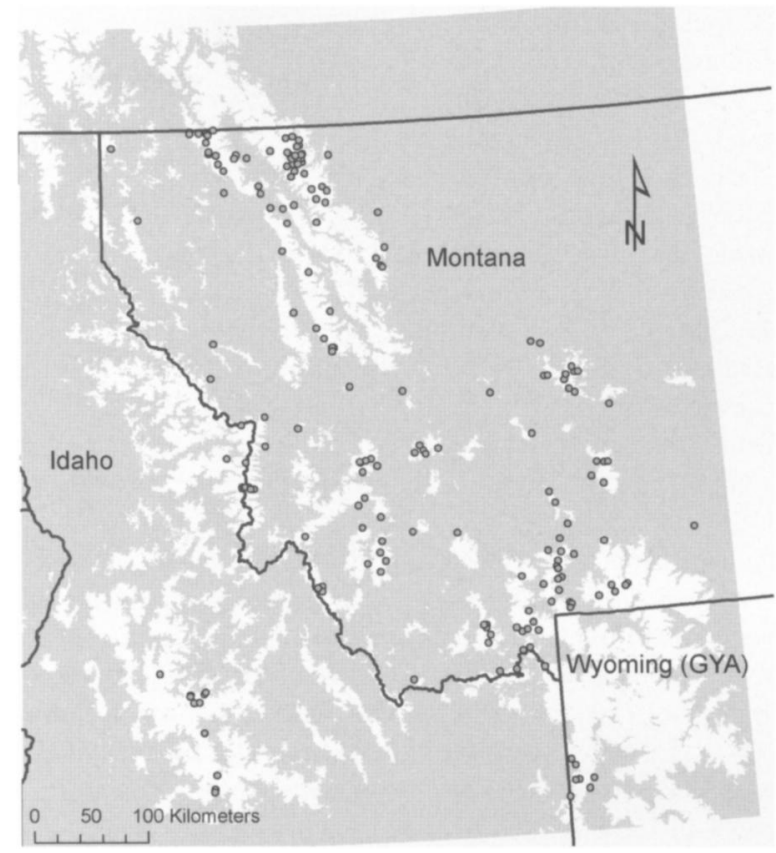

FIG. 1. Map of the northern U.S. Rockies. The white areas are locations of the spring snow cover bioclimatic envelope (J. P. Copeland et al., unpublished manuscript), whereas the gray areas do not have spring snow cover. Circles are locations of samples collected between 1989 and 2006. GYA stands for the Greater Yellowstone Area.

lations and areas of historical extirpation in the southern Rocky Mountains.

\section{Methods \\ Study area}

The study area consists of a region covering northern and central Idaho, western Montana, and northwest Wyoming (Fig. 1). The area is composed of discrete mountain ranges each characterized by high alpine areas (maximum elevation $3900 \mathrm{~m}$ ) and surrounded by wide areas of semiarid grasslands and irrigated agriculture (elevation $\sim 1400 \mathrm{~m}$ ). Within this landscape, areas characterized by persistent spring snow cover are fairly contiguous in the northwest portion of the study area, but become increasingly fragmented to the south and east, with the exception of the Greater Yellowstone Area (GYA), providing another large, contiguous area of persistent spring snow cover at the southern edge of the study area.

\section{Genetic samples and laboratory analyses}

Two-hundred ten wolverine tissue samples were examined in this analysis (Fig. 1). One hundred fortytwo samples were harvest samples collected by the Montana Department of Fish Wildlife and Parks between 1989 and 2006 while the remainder were collected between 1992 and 2007 as part of ongoing research efforts in Idaho, Montana, and Wyoming 
(Copeland 1996, Ulizio et al. 2006, Copeland et al. 2007, Inman et al. 2007, Squires et al. 2007).

All samples were analyzed at 16 microsatellite loci used in previous mustelid studies (Kyle and Strobeck 2001, 2002, Cegelski et al. 2003, 2006, Zielinski et al. 2006, Schwartz et al. 2007): $G g 3, G g 4, G g 7, M a 2, M a 8$, Ma9, Tt1, Tt4 (Davis and Strobeck 1998); Ggu101, Ggu216, Ggu234, Ggu238 (Duffy et al. 1998); Mvis020, Mvis72, Mvis075 (Flemming et al. 1999); and Lut604 (Dallas and Piertney 1998). We amplified microsatellites using protocols detailed in the respective sources. The resultant products were visualized on a LI-COR DNA analyzer (LI-COR Biotechnology, Lincoln, Nebraska, USA) and independently scored by two technicians before being accepted as reliable.

Mitochondrial DNA (mtDNA) patterns among wolverine sampling locations have been examined extensively (Wilson et al. 2000, Walker et al. 2001, Tomasik and Cook 2005, Cegelski et al. 2006, Schwartz et al. 2007). In this study we reexamined 17 samples taken from wolverines in the areas of persistent spring snow cover in the Crazy and Little Belt Mountains using the $344 \mathrm{bp}$ segment of the left domain of the mtDNA control region (see Shields and Kocher 1991 for protocol details). We use these mtDNA data as an independent test of our least-cost path corridor analysis, which was developed based on microsatellite data.

\section{Descriptive statistical genetic analyses}

Descriptive statistics such as the number of alleles per locus, Hardy Weinberg proportion tests (Bonferonni corrected), and expected and observed heterozygosity were calculated using GENALEX (Peakall and Smouse 2006) and GENEPOP (Raymond and Rousset 1996). Spatial autocorrelation between samples was estimated using GENALEX (Peakall and Smouse 2006) using 25 bins of $25 \mathrm{~km}$, although the influence of various binning classes was investigated. Variance estimates for spatial autocorrelation were based on 9999 permutations and 999 bootstraps.

We used two measures of genetic distance in these analyses, the proportion of shared alleles $\left(D_{\mathrm{PS}}\right.$; Bowcock et al. 1994) and the pairwise individual-by-individual squared genetic distances of Smouse and Peakall (1999). Except for autocorrelation analyses, we only present the $\mathrm{D}_{\mathrm{PS}}$ results as the two were highly correlated (Mantel test; $P=0.01, r=0.942$ ).

\section{GIS modeling of the spring snow cover niche}

Aubry et al. (2007) found that the historical distribution of wolverine were consistent with the distribution of persistent spring snow; J. P. Copeland et al. (unpublished manuscript) used seven years of classified moderate resolution imaging spectroradiometer (MODIS) satellite images (Hall et al. 2006) from 2000 to 2006 at a $0.5-\mathrm{km}^{2}$ resolution to define a more detailed area of persistent snow. Specifically, Copeland et al. characterized persistent spring snow cover in the entire northern hemisphere based on a 21-day composite (24 April-15 May) of images. They found that $>99 \%$ of wolverine den sites and $>89 \%$ year-round telemetry locations were located within areas that were classified as having persistent spring snow in at least one of the seven years for which data were available. We used Copeland et al.'s area to test if this bioclimatic niche facilitated wolverine gene flow. While the seven-year window used by Copeland et al. is limited by available data, it was important to identify an area which encloses virtually all den sites. Therefore, we can say that effectively all wolverines that mated and transferred genes within this landscape were born within the areas identified as having persistent spring snow, and thus we can be reasonably certain that we are not missing any potential sources of wolverine genes when analyzing these landscapes.

We built hypothetical resistance surfaces by setting the value of areas not snow covered to resistances of 5 , $10,15,20,50$, and 100 per raster while keeping snowcovered raster resistance costs at 1 . We used the ArcView (Environmental Systems Research Institute, Redlands, California, USA) extension PATHMATRIX (Ray 2005) and our own ARC Macro Language scripts (Cushman et al. 2006) to compute pairwise least-cost paths between all wolverine locations for each resistance surface. Additionally, we computed the pairwise straight-line (Euclidean) distances between wolverine locations (equivalent to least-cost paths with all rasters set to 1) in ArcView. Following Cushman et al. (2006), we used Mantel tests to determine correlation significance between matrices of pairwise movement costs and genetic distances, and partial Mantel tests to separate the effects of remaining in snow areas from those due to Euclidean distance. All Mantel and partial Mantel tests were conducted using the Ecodist library (Goslee and Urban 2007) in program R (available online). ${ }^{6}$ There has been debate regarding the use of partial Mantel tests (see Raufaste and Rousset 2001, Castellano and Balletto 2002); however, this approach is still the most commonly used method (e.g., Walker et al. 2008) for examining the association among distance matrices in the genetics literature.

\section{Corridor analysis and population subdivision}

We overlaid a $15 \times 15 \mathrm{~km}$ grid of locations across the study area, eliminating those grid nodes that were not in areas characterized by spring snow to model corridors connecting spring snow areas large enough to support wolverine reproduction. This density of nodes was based on minimum female home range size (Banci 1994) and guaranteed that at least one grid node would occur in each snow-covered area large enough to support at least one resident female wolverine (Krebs et al. 2007). We then computed pairwise least-cost paths between all

\footnotetext{
${ }^{6}\langle\mathrm{r}$-project.org/ $\rangle$
} 
nodes. We applied a $2500 \mathrm{~m}$ radius parabolic kernel around each one-raster wide path (Cushman et al. 2009) on the assumption that the least-cost paths represented the central tendency of wolverines whose actual paths imperfectly followed least-cost routes due to small-scale behavioral choices by individual animals. We then summed kernels associated with each least-cost path at each raster such that the highest values were associated with those areas having the highest density of least-cost wolverine paths. These computer-generated corridors simulated dispersals associated with a well-distributed population of wolverines. Our rationale was that the more paths that crossed an area, the more important it would be for dispersal, assuming that wolverines were well distributed throughout the study area. Additionally, we computed average pairwise cost distances associated with moving from each start location to all other start locations to estimate the relative isolation of each location given a well-distributed population.

Subsequently, we repeated this corridor analysis for areas extending from the Greater Yellowstone Area to the southern extent of the wolverine's historical distribution in the Rocky Mountains (Aubry et al. 2007) to evaluate the relative resistances and locations of possible colonization pathways and to infer historical movement paths.

\section{Isolation-by-resistance}

McRae and Beier (2007) suggested that isolation-byresistance as estimated by electrical circuit theory could better describe gene flow than least-cost path modeling. We therefore generated cost path models using McRae's (2006) CIRCUITSCAPE software. However, computational limits of their program required aggregation of rasters in our base map to one-tenth the number of rasters using the majority rule for raster reclassification. To compare the electrical circuit theory approach to least-cost paths, we re-ran the least-cost path models on these aggregated maps and conducted Mantel tests as for cost distance matrices derived from both circuit and least-cost path approaches.

\section{Effective population size}

Using only those samples from the main part of the Rocky Mountains (i.e., eliminating samples from the Crazy and Belt Mountains, as Cegelski et al. 2003 suggested they form a different subpopulation), we estimated the effective population size and $95 \%$ credible limits of the estimate via summary statistics and approximate Bayesian computation methods using $\mathrm{ONe}$ SAMP (Tallmon et al. 2008). To determine the temporal stability of the wolverine population, we subdivided the samples into three time frames and used ONeSAMP to estimate effective population size in each frame.

\section{RESULTS}

\section{Descriptive statistical genetic analyses}

Despite the broad scale of sampling, the majority of loci were in Hardy-Weinberg proportions; loci $G g 7$,
Ggu216, and Mvis020 were out of Hardy-Weinberg proportions. The tests for heterozygote excess using all loci showed no significant heterozygote excess, while the tests for heterozygote deficits produced highly significant results $\left(P<0.001 ; F_{\mathrm{IS}}=0.075\right)$. Overall, 65 alleles were detected, mean number of alleles per locus was 4.06 (SE $=0.28)$, expected heterozygosity was $0.504(\mathrm{SE}=0.049)$, and observed heterozygosity was $0.473(\mathrm{SE}=0.052)$. The first six bins ( $25 \mathrm{~km}$ per bin) in the spatial autocorrelogram were positively autocorrelated (using criteria of Peakall and Smouse 2006), suggesting that wolverine are spatially more related than by chance at distances up to $150 \mathrm{~km}$ (Fig. 2). Altering the number and width of bins did not significantly change these results (data not shown). Additionally, Mantel tests suggested a significant positive correlation between genetic distance and Euclidean distance $\left(r_{\mathrm{M}}=0.215, P=0.001\right)$.

Analysis of the mtDNA control region showed that $100 \%(5 / 5)$ of the Crazy Mountains samples in the areas with spring snow were haplotype I and $70 \%(7 / 10)$ of the Little Belt Mountains samples found in the areas with spring snow were haplotype I, with the remainder being haplotype A.

\section{Corridor analysis and population subdivision}

Significant positive correlations between genetic distance and cost distance were detected for all cost models based on spring snow cover with correlations increasing as we increased resistance for movement across areas not covered by spring snow (Fig. 3), although the relationship was asymptotic and correlations did not appreciably improve for models with non-snow costs above 20 (Fig. 3). In all cases, cost models based on snow cover had significantly stronger correlations with observed genetic distances than Euclidean models.

Given that both Euclidean distance and cost distance were significantly related to genetic distance, we used partial Mantel tests to remove the influence of each variable while correlating the other with genetic distance. For all cost models based on snow cover, there was no significant relationship between genetic distance and Euclidean distance once the spring snowbased correlation was removed (Table 1). However, the relationship between genetic distance and cost distance was always significant when Euclidean distance was partialled out of the relationship (Table 1).

The least-cost path analysis among all pairs of systematically gridded points suggested several important wolverine corridors connecting areas of spring snow cover (orange paths in Fig. 4). Plotting the average cost distance between all pairs of individuals in the northern U.S. Rocky Mountains suggested a bimodal distribution of cost distances, with a few isolated locations (Fig. 4). Fig. 4 showed smaller average costs between individuals in the Bitterroot Mountains on the Idaho-Montana border and within the Bob Marshall Wilderness complex than between the southern GYA and the Gallatin Mountains. The largest average costs were associated 


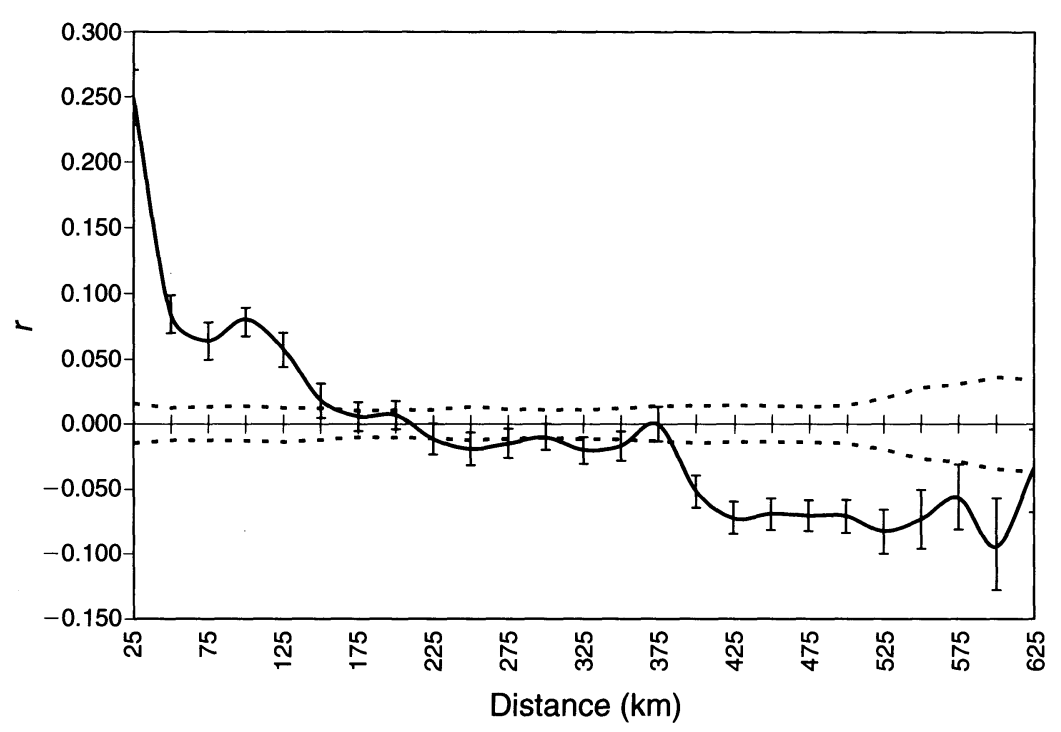

FIG. 2. Decline in the genetic correlation of wolverines ( $r$; Peakall and Smouse 2006) with geographic distance. Dashed lines indicate permuted $95 \%$ confidence bounds and the error bars are the $95 \%$ confidence intervals generated by bootstrapping.

with movements between the Little Belt and Crazy Mountains and all other points. Extrapolating the same spring snow relationships from the northern Rocky Mountains to Colorado and Utah (where wolverines were persistent until the early 20th century; Aubry et al. 2007) showed average cost distances between the GYA and Colorado via the spring snow cover layer were much greater than distances within the northern Rocky Mountains (i.e., the distributions did not overlap; Figs. 4 and 5).

\section{Isolation-by-resistance}

CIRCUITSCAPE results were similar to the least-cost path results in that genetic distance was correlated with Euclidean distance $\left(r_{M}=0.180, P=0.001\right.$; Table 2). Genetic distance was also correlated with spring snowbased cost distances derived via circuit theory $\left(r_{M}=\right.$ $0.224, P=0.001$ ), and with spring snow-based cost distances derived via circuit theory after controlling for Euclidean distance $\left(r_{M}=0.150, P=0.002\right)$. However, in all cases less variance was explained using circuit theory than through least-cost-path derived models. Resistance models associated with circuit theory were less effective at finding the effects of gene flow through snow areas than were models based on least-cost paths. In addition, genetic distance was significantly correlated with Euclidean distance after controlling for cost distances derived via circuit theory $\left(r_{M}=0.074, P=0.001\right.$; Table 2). However, this result is likely due to the aggregation of rasters required to meet computational demands of the CIRCUITSCAPE program. Using a least-cost path approach with the aggregated spring snow layer also failed to partial Euclidean distance from resistance effects (Table 2).

\section{Effective population size}

Effective population size, calculated using ONeSAMP (Tallmon et al. 2008), was 35 (credible limits $=28-52$ ) and was found not to change over time $\left(N_{\mathrm{e} 89-94}=33\right.$, credible limits 27-43; $N_{\text {e95-00 }}=35$, credible limits $28-57$; $N_{\mathrm{e} 01-06}=38$, credible limits 33-59).

\section{Discussion}

\section{Spring snow bioclimatic niche}

The spring snow bioclimatic niche, which has been identified as important for predicting wolverine denning, range, and year-around telemetry locations (J. P. Copeland et al., unpublished manuscript), also provides a spatial explanation for wolverine gene flow. While Euclidean distance was significantly correlated with genetic distance, partial Mantel tests suggested that it

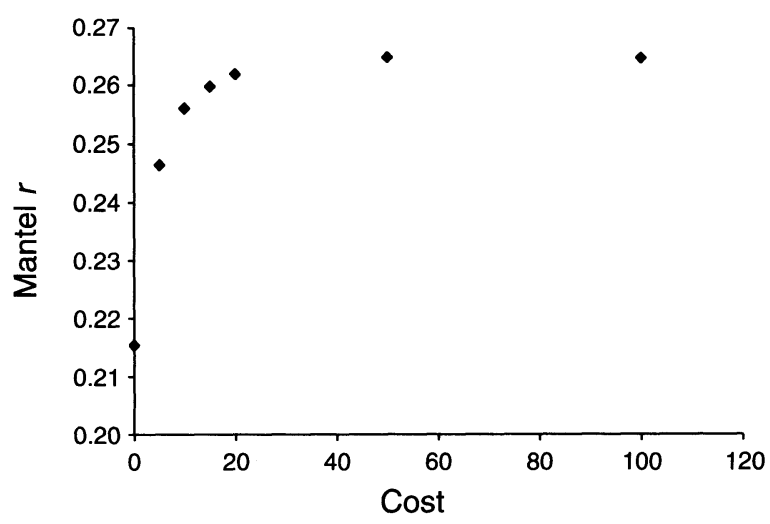

FIG. 3. Plot of $r$ value (Mantel tests) vs. cost (ecological cost distance, unitless) used for non-spring snow cover cells in the least-cost path modeling. The relationship asymptotes at a resistance of 20. 
TABLE 1. Partial Mantel results comparing matrices of genetic distance among all pairs of individuals, Euclidean distances among all pairs of individuals, and least-cost paths through the ecological cost layer, where higher costs (from a resistance of 5-50) were assigned to nonspring snow cover cells.

\begin{tabular}{llrc}
\hline \hline \multicolumn{1}{c}{ Correlation } & \multicolumn{1}{c}{ Partialled out } & Mantel $r$ & $P$ \\
\hline$D_{\mathrm{PS}} \times$ Euclidean distance & non-spring snow cost $=5$ & -0.046 & 0.902 \\
$D_{\mathrm{PS}} \times$ Euclidean distance & non-spring snow cost $=10$ & -0.018 & 0.685 \\
$D_{\mathrm{PS}} \times$ Euclidean distance & non-spring snow cost $=15$ & -0.004 & 0.530 \\
$D_{\mathrm{PS}} \times$ Euclidean distance & non-spring snow cost $=20$ & 0.005 & 0.436 \\
$D_{\mathrm{PS}} \times$ Euclidean distance & non-spring snow cost $=50$ & 0.024 & 0.266 \\
$D_{\mathrm{PS}} \times$ non-spring snow cost $=5$ & Euclidean distance & 0.131 & 0.001 \\
$D_{\mathrm{PS}} \times$ non-spring snow cost $=10$ & Euclidean distance & 0.143 & 0.001 \\
$D_{\mathrm{PS}} \times$ non-spring snow cost $=15$ & Euclidean distance & 0.150 & 0.001 \\
$D_{\mathrm{PS}} \times$ non-spring snow cost $=20$ & Euclidean distance & 0.153 & 0.001 \\
$D_{\mathrm{PS}} \times$ non-spring snow cost $=50$ & Euclidean distance & 0.160 & 0.001 \\
\hline
\end{tabular}

Note: The genetic distance measure used was the proportion of shared alleles $\left(D_{\mathrm{PS}}\right)$.

was a nuisance variable and not the main factor that strongly influenced gene flow: persistent spring snow cover had a significant independent effect on genetic distance when we controlled for Euclidean distance, but the converse was not true. MtDNA results suggested some degree of isolation of the GYA and greater isolation of the Little Belt and Crazy Mountains (see Appendix) acting as independent support for our corridor modeling derived from microsatellite data.

\section{Wolverine gene flow and substructure in light of spring snow}

There have been several analyses that have evaluated wolverine gene flow and substructure in North America (Kyle and Strobeck 2001, 2002, Cegelski et al. 2003, 2006, Guillot et al. 2005). All of these analyses, however, were based exclusively on patterns of genetic clustering; explanations for the observed patterns were post hoc. Here we initiated an analysis with a definition of the breeding range for wolverines. The areas of persistent spring snow defined by J. P. Copeland et al. (unpublished manuscript) enclosed $>99 \%$ of wolverine dens in North America and Scandinavia. The locations of the 210 samples used in this study indicate that many of the identified areas contain wolverine (Fig. 1). Importantly, these data also show that the areas exterior to Copeland's area of spring snow do not contain reproductive populations.

Further, we know that there are strong patterns of spatial correlation that extend over $100 \mathrm{~km}$ within this population, suggesting gene flow but not panmixia across the population and within subunits. The presence of a strong correlation gradient likely invalidates clustering approaches, particularly when sampling is uneven (Schwartz and McKelvey 2009). In these situations an intrinsically gradient-based approach such as the resistance modeling we applied is more appropriate.

\section{Landscape connectivity, corridors, and climate change}

Increasing human presence in the western United States has led to increasing development of open spaces
(Gude et al. 2007) that historically served to connect isolated habitats. This trend has led both nongovernment organizations and government agencies to consider the importance of biological corridors for conservation planning (available online). ${ }^{7}$ Maps of corridors are commonly used by land management groups, but unfortunately are most often the product of expert opinion rather than empirical data. The approach used in this study: collecting a spatially distributed genetic sample, hypothesizing likely landscape resistance factors, correlating genetic patterns with putative resistances to determine their validity, and finally using the derived models to infer likely corridors provides a rapid, relatively low cost, empirical approach to determining corridors for many species. We have used these methods to develop corridors maps for bears (Cushman et al. 2009) and are currently analyzing genetic patterns for fisher (Martes pennantii), marten (Martes americana), and several species of small mammals. Developing empirically based corridors models on the same landscape allows us to test the concept of "umbrella corridors," or multispecies corridors, where it is inherently assumed that a corridor for one species is appropriate for another.

By linking genetic relatedness with an ecologically derived understanding of wolverine distribution, we offer a data-derived understanding of a landscape feature that facilitates movement, which may become useful for land-use planning such as conservation easement targets. In addition, we present likely paths for the natural recolonization of wolverine into Colorado, and show why, due to high average costs associated with those movements, natural recolonization is challenging. Additionally, we propose a central "artery" for wolverine gene flow in the Rocky Mountains, centered on the Bitterroot Mountain chain bordering western Montana and eastern Idaho. Based on least-cost path rules, this putative corridor links wolverines in the north (Bob Marshall Wilderness, Glacier National Park, northern Idaho) and wolverines

\footnotetext{
${ }^{7}\langle$ http://www.westgov.org/wga/publicat/wildlife08.pdf $\rangle$
} 


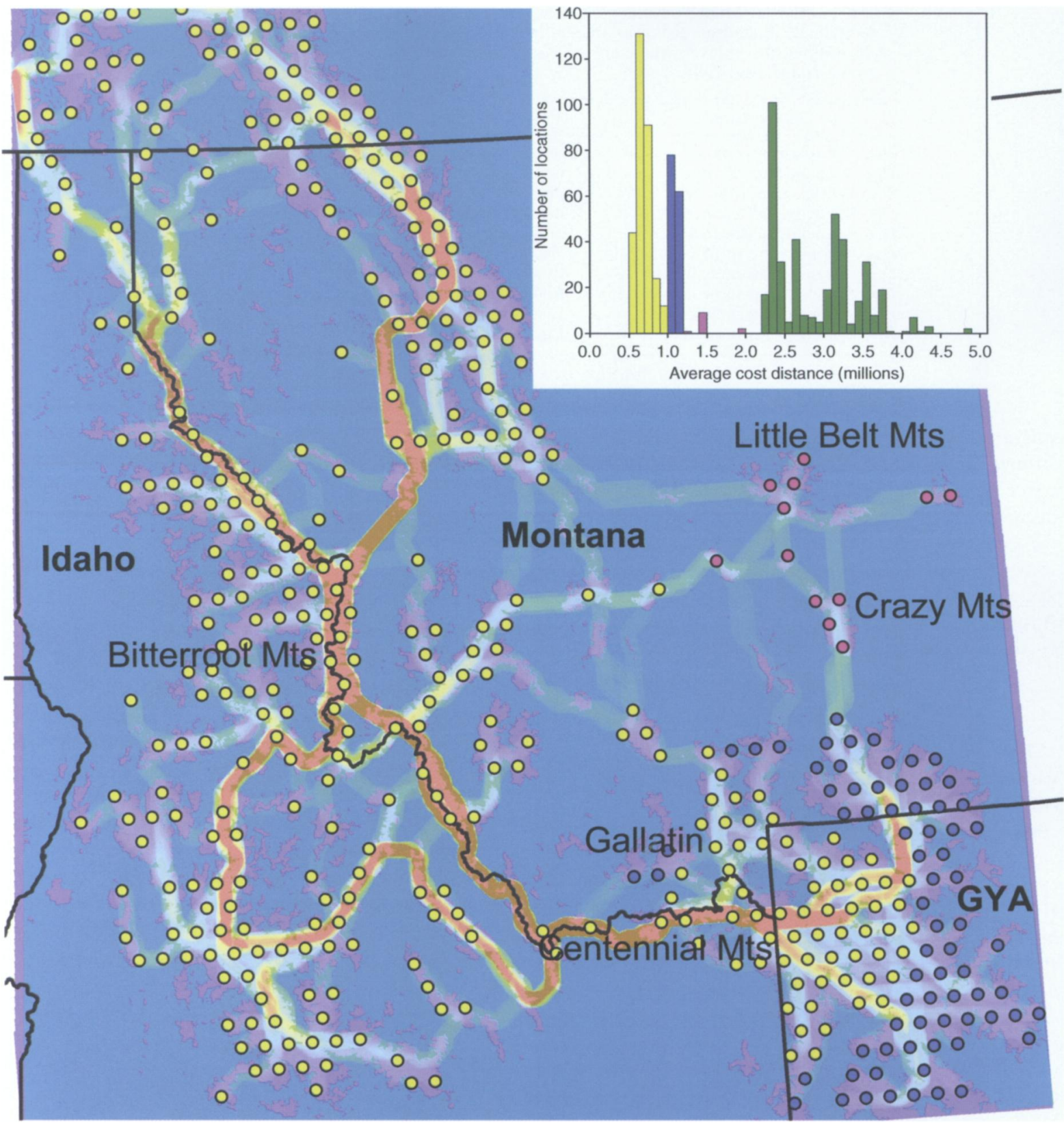

FIG. 4. Map of the northern U.S. Rockies with cumulative least-cost paths between systematically placed locations (circles) in spring snow cover cells. Paths in orange are predicted to be used more often than those in cooler colors. The color of the circle corresponds to the average cost distance between that location and all other locations, based on our models. The inset graph in the upper right is the cumulative plot of average cost distance (in millions of cost units) between each systematically placed location and all other locations. The graph was divided into four modes (three within the northern U.S. Rockies, and one between the Greater Yellowstone Area and Colorado). The yellow mode has the lowest average cost distances (within the northern U.S. Rockies), the blue bars the next lowest, the pink bars (Crazy and Little Belt Mountains) have the greatest average cost distances in the northern U.S. Rockies, and the green bars show the distances between all points from Colorado to the Greater Yellowstone Area.

in the south (GYA, Central Idaho). Furthermore, an often proposed corridor through the Centennial Mountains (on the border between Montana and Idaho) is supported by these analyses. These proposed corridors, while empirically supported, still should be evaluated with independent empirical testing (e.g., through the use of GPS collars on wolverines that may disperse or through extensive noninvasive genetic monitoring).

\section{Limits of our analysis}

Whereas least-cost path analyses are powerful landscape genetic tools that allow the evaluation of 


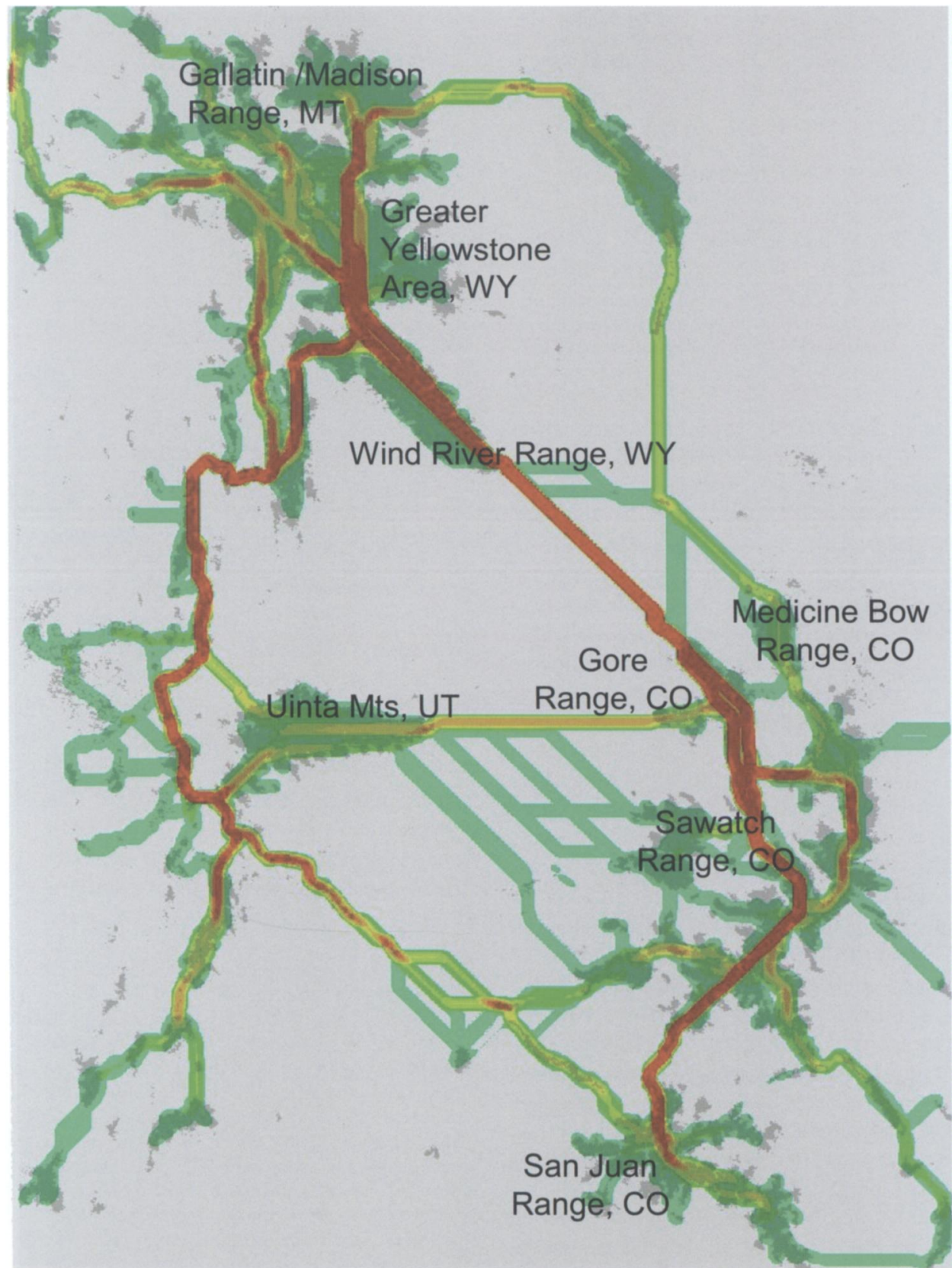

FIG. 5. Map of least-cost paths between Colorado (CO) to the Greater Yellowstone Area (in Wyoming [WY] and Montana $[\mathrm{MT}])$. Areas in red were used more often than those in cooler colors.

biological factors that influence substructure, they are not a panacea. One particular problem, associated with many genetic analyses, is that the inferred time frame can be unclear. This is especially true for species with large effective population sizes, as drift is a function of effective population size and time (Nei and Chakravarti 1977). In the Rocky Mountains of the United States, the effective population size for wolverine is extremely small (35 individuals), and thus observed substructure would be caused by processes that occur on the order of only a few generations. However, single-sample estimators for effective population size are recent developments, thus their sensitivity to factors such as population structure remain largely unknown. Migration from other populations, however, is likely not an issue as gene flow from the main part of Canada appears minimal (Kyle and Strobeck 2002, Cegelski et al. 2006). Only three haplotypes have been discovered in the Rocky Mountains compared to the 13 haplotypes detected in Canada, suggesting marked separation between these samples. 
TABLE 2. Mantel and partial Mantel tests from circuit theory (distance Circuit $_{\text {) }}$ and least-cost path modeling with aggregated cells (distance Aggregated). $_{\text {. }}$.

\begin{tabular}{llcc}
\hline \hline \multicolumn{1}{c}{ Correlation } & \multicolumn{1}{c}{ Matrix partialled out } & Mantel $r$ & $P$ \\
\hline$D_{\mathrm{PS}} \times$ Euclidean distance & & 0.180 & 0.001 \\
$D_{\mathrm{PS}} \times$ ecological distance & & 0.224 & 0.001 \\
$D_{\mathrm{PS}} \times$ Euclidean distance & & 0.074 & 0.001 \\
$D_{\mathrm{PS}} \times$ ecological distance $_{\text {Circuit }}$ & ecological distance & \\
$D_{\mathrm{PS}} \times$ ecological $_{\text {Cistance }}$ & Euclidean distance & 0.150 & 0.002 \\
$D_{\mathrm{PS}} \times$ Euclidean distance & & 0.242 & 0.001 \\
$D_{\mathrm{PS}} \times$ ecological distance $_{\text {Aggregated }}$ & ecological distance $_{\text {Aggregated }}$ & 0.109 & 0.001 \\
\hline
\end{tabular}

Notes: We used an ecological resistance of 20 in non-spring snow cover cells. The base map was the same as Fig. 1, except every 10 cells were aggregated into one cell due to computing limitations. The genetic distance measure used is the proportion of shared alleles $\left(D_{\mathrm{PS}}\right)$.

Given that there are no other potential source populations, gene flow would not be strongly influencing our effective population size estimates, and therefore the likelihood that detected patterns are based on recent phenomena.

Recently, circuit theory has been suggested as a more powerful approach to elucidate gene flow compared to least-cost path models (McRae and Beier 2007). For example, McRae and Beier (2007) used a population approach (as compared to our individual-based approach) and found circuit theory to be an improvement for explaining genetic distance among 12 wolverine populations. However, resistance modeling using circuit theory did not lead to improved correlations in this study. Theoretically, circuit theory should provide better fit to gene flow by generating different gene flow rates across areas where populations are extensive compared to areas where populations are narrowly distributed along linear corridors (McRae and Beier 2007). The two models, however, converge in narrow areas. Wolverine living at the southern extent of their North American range occur in bands of habitat that are often linear and follow major mountain chains (Fig. 1), supporting the use of least-cost path analysis in our study. More comparison between these techniques will be necessary to determine those situations in which one approach will outperform the other.

An additional limitation of our analysis is that our samples were collected over multiple (three) generations, although there is evidence of population stability over time. Furthermore, these samples were from trapped animals which, while coming from both sexes, may have had a social or age bias. Another limitation of this analysis is that the landscape was defined in terms of a single variable, persistent spring snow cover. Other leastcost path analyses have worked with several factors (four in Cushman et al. 2006) and varying levels of each factor allowing comparison of many models. Our goal here was specifically to test one bioclimatic association shown to be predictive of wolverine dens and year-round habitat use. Future work that incorporates other important landscape features, such as human development, could refine our understanding of wolverine gene flow.

\section{Conclusion}

Overall, this research suggests that areas characterized by persistent spring snow cover, which in previous studies have been shown to strongly correlate with wolverine denning locations and year-round movement, also is correlated with gene flow. This spring snow-cover niche has the biologically important elements of snow during the winter and spring, and acts as a surrogate for wolverine's within-home range movements and dispersals year-round. In addition, we identified potential movement corridors that may be critical for the persistence of wolverines. Unfortunately, spring snow cover, and the bioclimatic niche that it indicates, is likely to continue to be strongly impacted by global climate change (Mote et al. 2005), threatening wolverine throughout their geographic distribution.

\section{ACKNOWLEDGMENTS}

We thank the Lolo Pass Redevelopment Project, the Federal Highway Administration, and the Idaho Transportation Department for supporting field efforts on wolverines in the Bitterroot Mountains, especially D. Davis and W. Melquist. We thank C. Engkjer for laboratory assistance, as well as the many field assistants who collected samples, including $\mathrm{R}$. Yates, J. Wilmot, T. McCue, M. Packila, T. Ulizio, and B. Jimenez. We also thank J. Tucker and P. Beier for comments on an earlier version of this manuscript. M. K. Schwartz was supported during parts of this work by a PECASE award. We thank the following groups for providing funding: Bridger-Teton National Forest Challenge Cost Share Program, Bullitt Foundation, Canyon Creek Foundation, Caribou-Targhee National Forest Challenge Cost Share Program, Disney Wildlife Conservation Fund, Doris Duke Charitable Foundation, Greater Yellowstone Coordinating Committee, IDF and $G$ Wildlife Grants Program, Laura Moore-Cunningham Foundation, Montana Department of Fish, Wildlife and Parks, National Fish and Wildlife Foundation, New York Community Trust, Richard King Mellon Foundation, Tapeats Fund, Wilburforce Foundation, Wyoming Game and Fish State Wildlife Grants Program, and private individuals.

\section{Literature Cited}

Allendorf, F. W., and G. Luikart. 2006. Conservation and the genetics of populations. Blackwell, London, UK.

Aubry, K. B., K. S. McKelvey, and J. P. Copeland. 2007. Distribution and broadscale habitat relations of the wolverine in the contiguous United States. Journal of Wildlife Management 71:2147-2158. 
Banci, V. 1994. Wolverine. Pages 99-122 in L. F. Ruggiero, K. B. Aubry, S. W. Buskirk, L. J. Lyon, and W. J. Zielinski, editors. The scientific basis for conserving forest carnivores in the western United States. U.S. Forest Service, General Technical Report RM-254.

Bowcock, A., A. Ruiz-Linares, J. Tomfohrde, E. Minch, J. Kidd, and L. Cvalli-Sforza. 1994. High resolution of human evolutionary trees with polymporphic microsatellites. Nature 368:455-457.

Bowne, D. R., and M. A. Bowers. 2004. Interpatch movements in spatially structured populations: a literature review. Landscape Ecology 19:1-20.

Castellano, S., and E. Balletto. 2002. Is the partial Mantel test inadequate? Evolution 56:1871-1873.

Cegelski, C., L. Waits, and N. Anderson. 2003. Assessing population substructure and gene flow in Montana wolverines (Gulo gulo) using assignment-based approaches. Molecular Ecology 12:2907-2918.

Cegelski, C. C., L. P. Waits, N. J. Anderson, O. Flagstad, C. Strobeck, and C. J. Kyle. 2006. Genetic diversity and population structure of wolverine (Gulo gulo) populations at the southern edge of their current distribution in North America with implications for genetic viability. Conservation Genetics 7:197-211.

Copeland, J. P. 1996. Biology of the wolverine in central Idaho. University of Idaho, Moscow, Idaho, USA.

Copeland, J. P., J. Peak, C. Groves, W. Melquist, K. S. McKelvey, G. W. McDaniel, C. D. Long, and C. E. Harris. 2007. Seasonal habitat associations of the wolverine in Central Idaho. Journal of Wildlife Management 71:2201-2212.

Coulon, A., G. Guillot, J.-F. Couson, J. M. A. Angibault, S. Aulagnier, B. Cargnelutti, M. Galan, and A. J. M. Hewison. 2006. Genetic structure is influenced by landscape features: empirical evidence from a roe deer population. Molecular Ecology 15:1669-1679.

Cushman, S. A., K. S. McKelvey, J. Hayden, and M. K. Schwartz. 2006. Gene-flow in complex landscapes: testing multiple hypotheses with causal modeling. American Naturalist 168:486-499.

Cushman, S. A., K. S. McKelvey, and M. K. Schwartz. 2009. Evaluating habitat connectivity and mapping of corridors between Yellowstone National Park and the Canadian Border with landscape genetics and least cost path analysis. Conservation Biology 23:368-376.

Dallas, J. F., and S. B. Piertney. 1998. Microsatellite primers for the Eurasian otter. Molecular Ecology 7:1247-1263.

Davis, C., and C. Strobeck. 1998. Isolation, variability, and cross-species amplification of polymorphic microsatellite loci in the family Mustelidae. Molecular Ecology 7:17761778 .

Duffy, A., A. Landa, M. O'Connell, C. Stratton, and J. Wright. 1998. Four polymorphic microsatellites in wolverine, Gulo gulo. Animal Genetics 29:63-72.

Fahrig, L., J. H. Pedlar, S. E. Pope, P. D. Taylor, and J. F. Wegner. 1995. Effect of road traffic on amphibian density. Biological Conservation 73:177-182.

Flemming, M. A., E. A. Ostrander, and J. A. Cook. 1999. Microsatellite markers for American mink (Mustela vison) and ermine (Mustela erminea). Molecular Ecology 8:13521354.

Gardner, C. L., W. B. Ballard, and B. H. Jessup. 1986. Long distance movement by an adult wolverine. Journal of Mammalogy 67:603.

Goossens, B., L. Chikhi, M. Ancrenaz, I. Lackman-Ancrenaz, P. Andau, and M. W. Bruford. 2006. Genetic signature of anthropogenic population collapse in orang-utans. PLoS Biology 4:285-291.

Goslee, S., and D. Urban. 2007. The ecodist package for dissimilarity-based analysis of ecological data. Journal of Statistical Software 22:1-19.
Gude, P. H., D. A. Hansen, and D. A. Jones. 2007 Biodiversity consequences of alternative future land use scenarios in Greater Yellowstone. Ecological Applications 17:1004-1018.

Guillot, G., A. Estoup, F. Mortier, and J. F. Cosson. 2005. A spatial statistical model for landscape genetics. Genetics 170 : 1261-1280.

Hall, D. K., G. A. Riggs, and V. V. Salomonson. 2006 MODIS/Terra snow cover daily L3 global $500 \mathrm{~m}$ grid V004, April 24-May 21, 2000-2006. National Snow and Ice Data Center, Boulder, Colorado, USA.

Hornocker, M. G., and H. S. Hash. 1981. Ecology of the wolverine in northwestern Montana. Canadian Journal of Zoology 59:1286-1301.

Inman, R. M., K. H. Inman, A. J. McCue, M. L. Packila, G. C. White, and B. C. Aber. 2007. Wolverine space use in Greater Yellowstone. Pages 1-20 in Wildlife Conservation Society, editor. Greater Yellowstone Wolverine Program, Cumulative Report. Wildlife Conservation Society, North America Program, Bozeman, Montana, USA.

Inman, R. M., R. R. Wigglesworth, K. H. Inman, M. K Schwartz, B. L. Brock, and J. D. Rieck. 2004. Wolverine makes extensive movements in Greater Yellowstone Ecosystem. Northwest Science 78:261-266.

Krebs, J., E. C. Lofroth, and I. Parfitt. 2007. Multiscale habitat use by wolverines in British Columbia, Canada. Journal of Wildlife Management 71:2180-2192.

Kyle, C. J., and C. Strobeck. 2001. Genetic structure of North American wolverine populations. Molecular Ecology 10:337347.

Kyle, C. J., and C. Strobeck. 2002. Connectivity of peripheral and core populations of North American wolverines. Journal of Mammalogy 83:1141-1150.

Lofroth, E. C., and J. Krebs. 2007. The abundance and distribution of wolverines in British Columbia, Canada. Journal of Wildlife Management 71:2159-2169.

Magoun, A. J., and J. P. Copeland. 1998. Characteristics of wolverine reproductive den sites. Journal of Wildlife Management 62:1313-1320.

Manel, S., M. K. Schwartz, G. Luikart, and P. Taberlet. 2003. Landscape genetics: the combination of landscape ecology and population genetics. Trends in Ecology and Evolution 18:189-197.

McRae, B. H. 2006. Isolation by resistance. Evolution 60:15511561.

McRae, B. H., and P. Beier. 2007. Circuit theory predicts gene flow in plant and animal populations. Proceedings of the National Academy of Sciences (USA) 104:19885-19890.

Moriarty, K. M., W. J. Zielinski, A. G. Gonzales, T. E. Dawson, K. M: Boatner, C. A. Wilson, F. V. Schlexer, K. L. Pilgrim, J. P. Copeland, and M. K. Schwartz. 2009. Wolverine confirmation in California after nearly a century: native or long-distance immigrant? Northwest Science 83: 154-162.

Mote, P. W., A. F. Hamlet, M. P. Clark, and D. P. Lettenmaier. 2005. Declining mountain snowpack in western North America. Bulletin of the American Meteorological Society 86:39-49.

Nei, M., and A. Chakravarti. 1977. Drift variances of Fst and Gst statistics obtained from a finite number of isolated populations. Theoretical Population Biology 11:307-325.

Pasitschniak-Arts, M., and S. Lariviere. 1995. Gulo gulo. Mammalian Species 499:1-10.

Peakall, R., and P. E. Smouse. 2006. GENALEX 6: genetic analysis in Excel. Population genetic software for teaching and research. Molecular Ecology Notes 6:288-295.

Raufaste, N., and F. Rousset. 2001. Are partial Mantel tests adequate? Evolution 55:1703-1705.

Ray, N. 2005. PATHMATRIX: a geographical information system tool to compute effective distances among samples. Molecular Ecology Notes 5:177-180. 
Raymond, M., and F. Rousset. 1996. Genepop (Version 3.1d): population genetics software for exact tests and ecumenicism. Journal of Heredity 86:248-249.

Saccheri, I. J., R. A. Nichols, and P. M. Brakefield. 2001. Effects of bottlenecks on quantitative genetic variation in the butterfly Bicyclus anynana. Genetical Research 77:167-181.

Schwartz, M. K., K. B. Aubry, K. S. McKelvey, K. L. Pilgrim, J. P. Copeland, J. R. Squires, R. M. Inman, S. M. Wisely, and L. F. Ruggiero. 2007. Inferring geographic isolation of wolverine in California using historical DNA. Journal of Wildlife Management 71:2170-2179.

Schwartz, M. K., and K. S. McKelvey. 2009. Why sampling matters: the effect of sampling and spatial autocorrelation on landscape genetic results. Conservation Genetics 10:441-452.

Schwartz, M. K., D. A. Tallmon, and G. Luikart. 1998. Using non-invasive genetic sampling methods and new analytical tools to detect population declines and minimize extinctions. Animal Conservation 1:293-299.

Shields, G. F., and T. D. Kocher. 1991. Phylogenetic relationships of North American ursids based on analysis of mitochondrial DNA. Evolution 45:218-221.

Smouse, P. E., and R. Peakall. 1999. Spatial autocorrelation analysis of individual multiallele and multilocus genetic structure. Heredity 82:561-573.

Squires, J. R., M. K. Schwartz, J. P. Copeland, L. F. Ruggiero, and T. J. Ulizio. 2007. Sources and patterns of wolverine mortality in western Montana. Journal of Wildlife Management 71:2213-2220.

Tallmon, D. A., A. Koyuk, G. Luikart, and M. A. Beaumont. 2008. ONeSAMP: a program to estimate effective population size using approximate Bayesian computation. Molecular Ecology Resources 8:299-301.
Tomasik, E., and J. A. Cook. 2005. Mitochondrial phylogeography and conservation genetics of wolverine (Gulo gulo) of northwestern North America. Journal of Mammalogy 86: 386-396.

Ulizio, T. J., J. R. Squires, D. H. Pletscher, J. J. Claar, L. F. Ruggiero, and M. K. Schwartz. 2006. The efficacy of obtaining genetic-based identifications from putative wolverine snow tracks. Wildlife Society Bulletin 34:1326-1332.

USFWS (U.S. Fish and Wildlife Service). 2008. Endangered and threatened wildlife and plants; 12-month finding on a petition to list the North American wolverine as endangered or threatened. Federal Register 73:12929-12941.

Walker, C. W., C. Vila, A. Landa, M. Linden, and H. Ellengren. 2001. Genetic variation and population structure in Scandinavian wolverine (Gulo gulo) populations. Molecular Ecology 10:53-63.

Walker, F. M., A. C. Taylor, and P. Sunnucks. 2008. Female dispersal and male kinship-based association in southern hairy-nosed wombats (Lasiorhinus latifrons). Molecular Ecology 17:1361-1374.

Waples, R. S., and C. Do. 2008. LDNE: a program for estimating effective population size from data on linkage disequilibrium. Molecular Ecology Resources 8:753-756.

Wilson, G. M., R. A. Van Den Bussche, P. K. Kennedy, A. Gunn, and K. Poole. 2000. Genetic variability of wolverines (Gulo gulo) from the Northwest Territories, Canada: conservation implications. Journal of Mammalogy 36:186-196.

Zielinski, W. J., F. V. Schlexer, K. L. Pilgrim, and M. K. Schwartz. 2006. Testing the efficacy of two methods for snaring hair from mesocarnivores. Wildlife Society Bulletin $34: 1152-1161$.

\section{APPENDIX}

Distribution of wolverine haplotypes in the U.S. Rocky Mountains (Ecological Archives E090-229-A1). 